\title{
A typology of strategy tool applications
}

\author{
Paul J Knott \\ College of Business and Economics, University of Canterbury, \\ Private Bag 4800, Christchurch, New Zealand \\ Telephone: +64 33642941 Fax: +64 33642020 \\ Email:paul.knott@canterbury.ac.nz
}

Purpose: To improve the success rate and quality of outcome when strategy tools are used in practical situations.

Methodology/approach: Draws on post-experience teaching and uses conceptual reasoning to propose a typology of tool applications.

Findings: The paper finds that strategy tools need to be used differently according to the problem needs, and hence proposes five generic modes of tool application. These draw on seven dimensions to codify the functions and cognitive characteristics in a given tool application.

Research limitations/implications: The modes of application are conceptually rather than empirically derived. The paper provides conceptual background that could be used in muchneeded empirical work on tool use in the strategy activity.

Practical implications: The typology could be used in teaching or facilitation to encourage and help with the design of tool adaptations that are coherent and well adapted to the situation. It provides a means for prior reflection on tool choice and application that could help reduce detrimental framing effects.

Originality/value: The paper highlights the centrality of user adaptation of tools and begins to codify the effects of tool enactment. It moves debate from the tools themselves to the application of tools, which has seldom been addressed in a systematic fashion. For practitioners it provides explicit guidance on the tool adaptation process.

Paper type: Research paper

Keywords: Strategy tool, strategy activity, strategy as practice, typology, framing, cognitive bias.

\section{Introduction}

This paper addresses the application of tools that guide strategic thinking, strategic decisionmaking and strategy implementation. Taking a strategy-as-practice perspective (Whittington 1996; Johnson, Melin and Whittington 2003), it is concerned with how managers use these tools as they undertake strategy activity. The term 'strategy tool' is used here to encompass the full range of concepts, ideas, techniques and approaches that structure or influence this activity. It centres on achieving constructive outcomes from tool use rather than on the validity of tool content. Examples of strategy tools within the scope of the paper are portfolio analysis models, core competence and resource-based approaches, hypercompetition, business process re-engineering, competitive analysis, the balanced scorecard, and lean manufacturing. These are defined here as 'strategy tools' because of their potential to influence the practice of strategy; they do not necessarily feature in conventional strategy textbooks. Where a term refers to a problem area, need or trend, it is not a tool and lies outside the scope of the paper. 
According to surveys, strategy tools are extensively used by businesses. Findings from Bain and Co. that on average companies claimed to use twelve such tools (Rigby 2001) are supported by a recent survey that found tool use to be a normal part of strategy workshops (Hodgkinson, Johnson, Whittington and Schwarz 2005). Tools are also a key component of typical MBA strategy teaching and the associated texts (Hill, Jones and Galvin 2004; Johnson, Scholes and Whittington 2004), and continue to be espoused in practitioneroriented strategy literature. Thus it is clear that strategy tools continue to be in extensive use, yet significant problems with this use are indicated by the widely recognised problem of management fads (Abrahamson and Fairchild 1999) and the associated emergence of 'guru scepticism’ (Crainer 1996).

This paper is concerned with tool use in the full range of strategic management activity. Strategy activity differs from other management activity in several important respects. It is non-routine, non-programmable, unique and creative (Harrison 1999). It is also more ambiguous, uncertain and complex than 'operational' management (Johnson, Scholes and Whittington 2004). Given this, a strategy tool is likely to assist with part of the activity rather than providing a substitute for the capabilities and experience of the manager (Whittington 1996). Rather than providing a blueprint, strategy tools act as a guide to thinking and a starting point for structuring the activity. For other types of management challenge, it may be possible to use tools in different and perhaps more deterministic ways. The activity of applying strategy tools is considered in more detail in the next section.

The scope of this paper is not limited to individual techniques used in strategy analysis, but extends to more comprehensive approaches and practices that require organisation-wide implementation. The viewpoint taken in the paper is that of individuals and small groups adopting strategy tools and applying them to their business. Organisation-level issues are not considered. The paper also does not attempt to address contextual influences on tool adoption, and hence does not address the question of tool diffusion.

Tool use by managers and consultants is not always explicit. This is particularly so for the use of concepts that are not closely defined. Implicit use may be especially prone to the biases and potential dysfunctional effects highlighted by this paper. However, the typology as presented refers to explicit tool use.

The paper has been developed through strategy teaching, and hence its output is most relevant to those teaching or learning how best to undertake strategy activity. The paper codifies knowledge that might exist at a tacit level in the minds of the most capable and experienced strategists.

\section{The tool application activity}

Whilst this paper highlights the variety of applications that may be made for strategy tools, these can be broadly described as guiding thinking and debate, or structuring analysis of complex and ambiguous situations. In such applications, although the tool does not in any way determine the thinking or outcome the potential would still seem to exist for it to channel and constrain thinking as it focuses and guides. This potential was considered by Mintzberg, Ahlstrand and Lampel (1998), who describe how the technique or organising framework used to structure information influences the insights and decisions that arise from that information. 
Mintzberg et al (1998) also describe how managers build mental models and frames that shape how strategy emerges. The use of strategy concepts or tools has the potential to influence these frames (Worren, Moore and Elliott 2002), and hence generate a focus on some elements of a company's strategic environment at the expense of others. This problem of framing represents a cognitive bias in decision making. Recent studies of this phenomenon suggest that the bias may be reduced by prior reflection on the part of the decision maker (Hodgkinson, Bown, Maule, Glaister and Pearman 1999), especially when presented with alternative problem frames (LeBoeuf and Shafir 2003). The typology presented in this paper is one means by which users might reflect on proposed tool applications and consider alternative tools or tool interpretations, hence reducing the potential for unwanted bias by active consideration of alternative problem frames.

An empirical illustration of the framing effect in strategy decision making was reported by Armstrong and Brodie (1994). In an experimental setting, managers presented with the Boston Consulting Group (BCG) growth-share model were more likely to opt for the unprofitable investment than those who had not. In this case, framing the problem in terms of the BCG matrix drew attention away from the basic profit calculations that might otherwise have led to the outcome set up as correct in terms of the given information.

Drawbacks due to the framing effect do not seem to be limited to the use of the BCG matrix. The core competence framework was presented by Prahalad and Hamel (1990) as an alternative approach to managing a corporate portfolio. This itself was found susceptible to channelling thinking in a detrimental fashion, including by Black and Boal (1994) who recognised that too great a focus on core competence could actually hinder competitiveness and make a firm susceptible to the 'Icarus Paradox'.

Similar potential adverse effects have been found with respect to tools and concepts in other areas of strategy. Lambert and Slater (1999) found that firms did not necessarily reap competitive benefits from pursuing faster product development cycles and on-schedule product launches. They suggested that firms should avoid pursuing these strategies too far if they were to avoid serious pitfalls. Similarly, Seely Brown and Duguid (2000) pointed to the limitations of introducing more formalised processes to try to improve efficiency. They found that in practice these efforts could easily destroy important patterns of activity that lie outside the domain of formal processes.

Given the above, it seems that any tool application is susceptible to the framing effect. It would also seem fruitless to search for an ideal tool whose application would be free from potentially unwanted effects. The desire for such tools seems to exist, however. De Kare Silver (1997) found that managers wanted tools that would be simple enough to be easily digested by a busy manager, yet also be specific to their needs in some measurable way. Unfortunately this combination of qualities is unlikely to be achieved given the finding that a theory or tool cannot be simultaneously general, simple and accurate (Daft and Weick 1984).

Instead, tool applications might be made more constructive by accepting the need for interpretation and adaptation, and providing assistance with this process. This is the rationale behind the typology presented here: by clarifying the functions and qualities inherent in a given tool application, it could facilitate application that is well matched with the business needs and hence more likely to be productive. The importance of good implementation to successful outcomes was recognised by Rigby (2001) in response to survey results showing greater satisfaction with management tools at successful companies 
than at unsuccessful ones. The perceived success of tool use seemed to be driven in part by how the user applied the tools; even tools with a poor rating overall were considered successful by some respondents.

The need for user adaptation of tools is driven not only by tool characteristics, but also by the diversity of business contexts. The design of a tool application might vary substantially according to firm size or whether the firm is for profit or not-for-profit; it might vary according to whether the purpose is to inspire or structure thinking or merely to provide legitimacy. Typologies relating to the tool application activity and its context include that of Daft and Weick (1984) for activity in relation to assumptions about the environment, and that of Jarzabkowski (2004) for environmental conditions in which tools are applicable. The typology presented in this paper does not address the environmental context, but instead tries to improve coherence in tool applications and highlights the limitations of a given application. In this way it addresses the suggestion by Rigby (1993) that how a tool is used is important as well as knowing which tool to use and when.

\section{Derivation of the typology}

Typologies are a key means by which management ideas are communicated. Their value lies in translating complex conditions into a parsimonious description that can explain outcomes and form the basis for action (Doty and Glick 1994). Influential strategy typologies include that of Porter (1980) for competitive strategy and that of Miles and Snow (1978) for strategic stance. Beyond strategy, another influential typology is the Jung typology for cognitive styles (Nelson and Quick 1996) and the related Myers-Briggs Type Index.

The central component of a typology is a set of interrelated ideal types, each representing a unique combination of attributes thought to be causally related to outcomes (Doty and Glick 1994). These ideal types must be related to a set of dimensions and causal explanations. In this paper, the ideal types are expressed as coherent combinations of tool application characteristics ('modes of application') in terms of seven dimensions.

Of the strategy typologies mentioned above, that of Porter was conceptually derived while that of Miles and Snow was derived empirically. The typology presented in this paper has been derived from a combination of empirical and conceptual work. The empirical component has been derived from MBA strategy teaching, including experience of tool use in projects and assignments. The typology has also been refined following direct use of an earlier version in an assignment: students were required to use the typology to explain their rationale for a specific tool application of their choice. In conceptual terms the typology is a synthesis of teaching-related observations and categories derived from existing literature.

The derivation of the typology makes it suitable for use as a conceptual scheme for further investigation of the tool application activity. Its direct application in managerial practice is limited by the common limitation of typologies that their power in codifying complex situations comes at the expense of precision. This and the relative lack of empirical validation suggest cautious application only, noting that the conceptually neat competitive strategy typology of Porter (1980) has only partly withstood empirical testing (CampbellHunt 2000). 


\section{Dimensions of tool application}

The dimensions were developed to represent the diversity of functions and characteristics involved in the activity of using a strategy tool. They are intended to be applied to particular instances of tool use, rather than to the tools themselves. Because they are produced on the basis that users should and will interpret tools to suit specific needs, in many cases they represent alternative applications of any given tool. Whilst a tool may lend itself to certain types of application, a different use may still be constructive.

The dimensions are summarised in Figure 1 and explained below. The purpose and meaning of these dimensions is clarified in the subsequent section that combines them into modes of tool application.

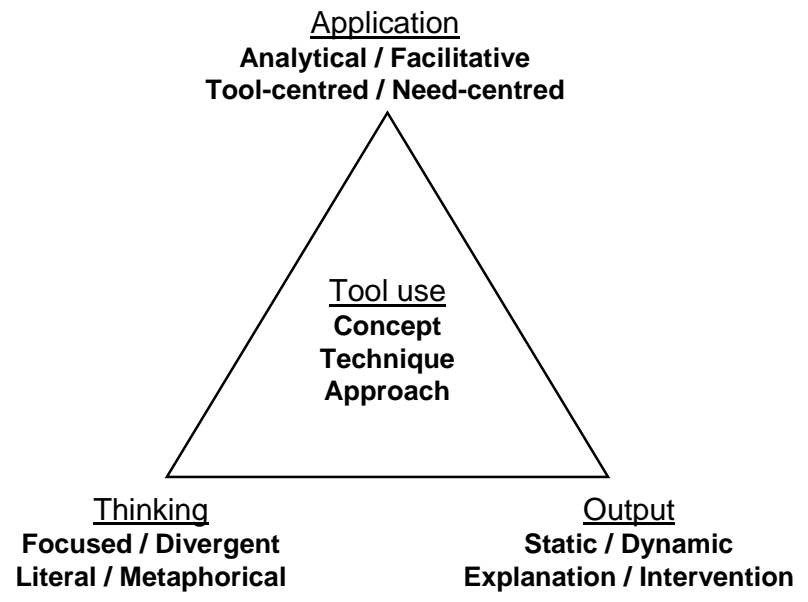

Tool

Concept

Technique

Approach

Application

Analytical

Facilitative

Tool-centred

Need-centred

\section{Thinking}

Focused

Divergent

Literal

Metaphorical

Output

Static

Dynamic

Explanation

Intervention

\section{Classification of form and scope of the tool as applied}

Perspective or idea providing a way of thinking. Not closely defined.

Specific and limited in scope. Multiple tools may easily be used.

Interconnected ideas forming an over-arching method of approaching a problem.

\section{Process characteristics of the activity of applying the tool}

Deals with parts and inter-relations of a subject, generating specific output.

Benefit is gained from the thought, interaction and debate stimulated by the use of the tool.

Choice and interpretation of information follows tool-derived categories.

Substantial customising is undertaken by users to match situation needs.

\section{Cognitive characteristics of the activity of applying the tool}

Well-defined, and specific to a given type of information and problem aspect and viewpoint. Involves expansive, creative, out-of-box thinking.

Deals directly and explicitly with the issues relating to the business situation.

Presents different subject matter to inspire fresh thinking about the business situation.

\section{Characteristics of the output from tool application}

Reflects a situation at a snapshot in time.

Reflects the evolution of forces influencing a situation over a period of time. Structured information that can be used as the basis for a course of action. Changes to people, resources, organisation or strategy.

Figure 1: Dimensions of strategy tool application 


\section{$\underline{\text { Tool }}$}

This classification separates the diverse form and scope of tool and concept applications in strategic thinking and decision-making. A tool applied as a concept does not draw on a detailed definition, but provides a general idea about how to approach a problem and select and interpret information. A concept is used as a source of ideas, or as a starting point for an initiative. A tool applied as a technique is used for a specific, limited purpose and forms the basis for detailed work. Multiple techniques may be used to look at different aspects of the same problem. Techniques are typically driven by an underlying concept, for example VRIO (Value-Rarity-Imitability-Organisation)(Barney 2002) could provide an analysis technique based on the concept of the resource-based view of the firm (Wernerfelt 1984). A tool used as an approach refers to the use of a set of interconnected techniques and concepts used as an over-arching method of managing a particular aspect of the business. The full implementation of the balanced scorecard (Kaplan and Norton 1996), as described in Application 1 below, illustrates this type of application.

\section{Thinking}

This classification considers the type of thinking inherent in the use of the tool. Its importance lies in the view expressed earlier in this paper that tools channel thinking as they guide it, resulting in an outcome that is driven in part by the nature of the tool.

Tools may be used to foster focused or divergent thinking. A divergent application refers to expansive, creative, out-of-box thinking. A focused application looks at a specific aspect of the problem, and hence limits the perspective, aspect of the problem, or range of information that will be taken into account. Applications structured around 2x2 matrices would typically be focused since they frame the problem in terms of two dimensions and four sets of actions. The generic competitive strategy matrix proposed by Porter (1980) lends itself to being used in this way. Focused thinking might be appropriate in the context of systematic strategic planning activity; divergent thinking might be better when innovative, proactive solutions are sought for an uncertain and rapidly changing environment (Graetz 2002). When used to foster divergent thinking, a tool might stimulate new ideas and provide for them to be collated and presented in ways that promote further creativity.

Tools and concepts may also be applied using literal or metaphorical thinking about the subject matter. Literal applications deal directly and explicitly with issues, influences and information on the business situation. Almost all tools and concepts taught in business schools (or found in strategy texts) are geared towards literal application. Metaphorical concepts are used to promote new thinking about business problems based on stimulating alternative subject matter, frequently sporting, historical (eg. Bose 2003, Kurke 2004) or military. They are often found in 'popular' management reading.

\section{Application}

This classification considers the application activity. Analytical applications deal with the parts and inter-relations of their subject, generating a specific output in a somewhat systematic fashion. Presentation of the analysis using such a tool can be used to support the case for a given decision. Analytical applications may be algorithmic, involving step-bystep procedures, or may be heuristic, acting as a guide to addressing a problem (Tsoukas 1993). Examples of algorithmic applications include formal use of techniques such as real 
options analysis or net present value. Following the guidance steps in implementing a balanced scorecard system (Kaplan and Norton 1996) would represent a heuristic application. In contrast, facilitative applications generate value principally through the thinking and debate that they help to generate; a SWOT or TOWS analysis is often used in a facilitative role in strategy workshops.

In a tool-centred application, the choice and interpretation of information follows the categories and criteria set by the tool. A strict application of Porter's five-force model for industry competition (Porter 1980) would be tool-centred. In a need-centred application, information and categories must be chosen by the user according to perceived needs. Toolcentred applications are prone to loss of value due to mismatch of theory with needs; needcentred applications are prone to loss of value where the chosen interpretation lacks coherence. Applications of the value chain (Porter 1985) will often be need-centred to the extent that the activities and categories need to be matched with those of the business. This adaptation is straightforward; others may be more convoluted and hence more prone to compromising coherence.

\section{$\underline{\text { Output }}$}

This classification characterises the output from the tool application. Outputs that are static are based on or represent the situation as it exists at a specific point in time (eg. industry attractiveness based on current competition, supply and demand conditions). Dynamic applications explicitly take into account the evolution of the relevant forces and factors over time (eg. analysis of technological trajectory or demand trends). The result of tool application may be intervention that affects the organisation, strategy, resources or people, for example when applying an approach to implementing strategic change. Tool applications often do not directly involve intervention, but instead provide explanation by presenting and structuring information (Tsoukas 1993)(eg. a report presenting analysis of a firm's situation).

\section{Generic modes of tool application}

The central component of the typology derives from the recognition that there is an inherent relationship between the characteristics described by the seven dimensions. This relationship is used to propose a set of coherent, constructive and achievable combinations of characteristics that constitute generic modes of application. These are designed to correspond to 'ideal types' in typology theory (Doty and Glick 1994). The assertion implied by the typology is that applications with combinations of characteristics close to one of the generic modes will be more successful than those with different combinations of characteristics. The five generic application modes are described below; example applications of three of these modes are given in the Application section that follows.

\section{Analytical mode}

An analytical application looks in detail at a specified aspect of the problem and seeks to generate specific output using a defined method. It would be used where a definitive output is desired that expresses the status of a problem. Adequate data are required along with a relevant and sufficiently defined heuristic or algorithmic technique. 


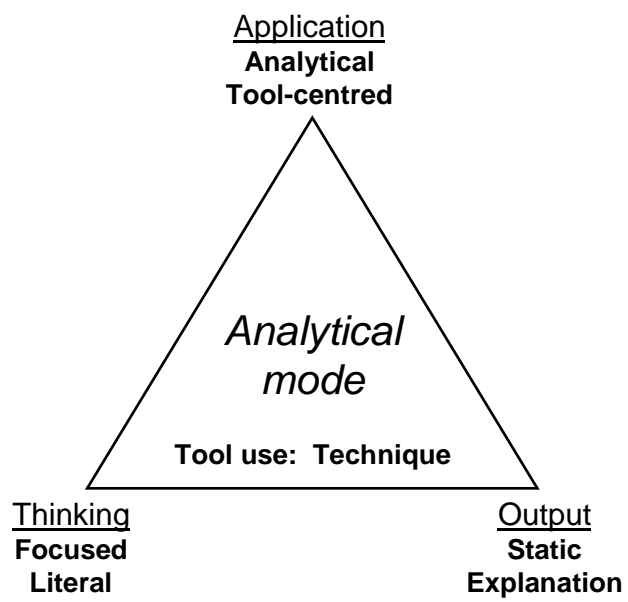

Figure 2: Analytical mode of application

In using a defined technique an analytical application is tool-centred in terms of categories, data and heuristic or algorithm. As such, the tool determines the perspective and scope. Furthermore, aspects of the problem not amenable to analysis or for which data are not available cannot easily be incorporated into an application of this type. For this reason the application supports focused thinking. Potential shortcomings of focused thinking may be addressed by applying complementary techniques giving an alternative perspective. This use of multiple tools is possible to the extent that the application is limited to analysis and does not require implementation through the business.

Since it is substantially driven by the tool, the output from applying an analytical technique is better used in support of decision making rather than as a specific prescription for action. Where analytical tools specify a prescription (for example some versions of the BCG growth-share matrix), good applications use them only as general guidance. Analytical applications are also likely to be static in strategic terms because of their requirement for specific sets of data. To be dynamic and still remain analytical would imply an unrealistic degree of predictive ability (if short-term analytical predictions are considered operational rather than strategic).

Tools that lend themselves to analytical application include real options analysis, shareholder value analysis and the 5-force model for industry competition (Porter 1980). The latter can be used to provide an explanation of the competitive forces impacting on a business and a prediction of profit potential based on these forces. Its application is normally tool centred in the sense that the same five forces are always used (interpretation is still needed in defining the industry and deciding on the strength of each force). Its use also has the potential to draw thinking away from other influences on profit and can encourage a static view of competition; it is often argued to have less value in highly turbulent industries. Dynamic interpretations are possible (see Mathews 2005), but their application then corresponds with that of the dynamic mode described below. 


\section{Dynamic mode}

A dynamic application focuses on the drivers of the evolution of a firm or its environment. By doing this it aims to generate working assumptions to help align investment and other strategic decisions with future conditions.

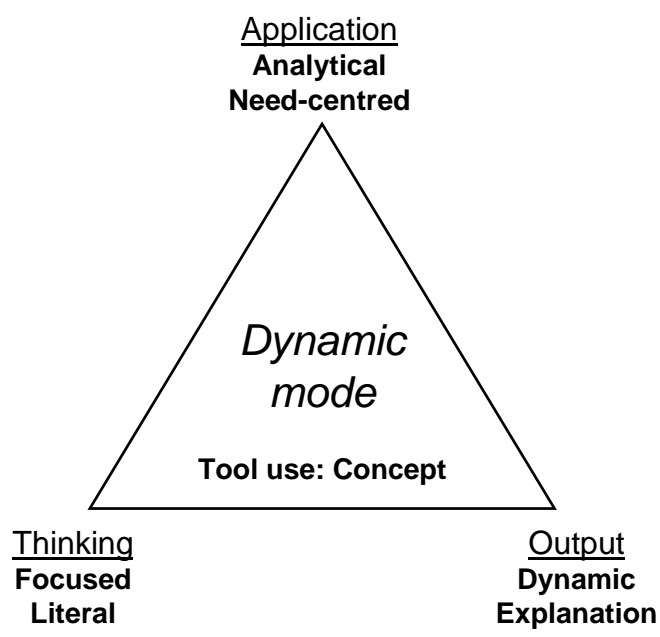

Figure 3: Dynamic mode of application

Dynamic applications inevitably deal with uncertainties as they involve a degree of prediction. Consequently the data and algorithm required for an algorithmic application will not be present. A dynamic application will be more heuristic in nature and will involve significant interpretation centred on assumptions that should be matched to the business needs. As such, it should be considered a need-centred interpretation of a particular concept. Concepts that lend themselves to this type of application include the dynamic capabilities framework (Teece, Pisano and Shuen 1997), the industry life cycle (Porter 1980), and strategic intent (Hamel and Prahalad 1989). Each of these provides a specific viewpoint that can form the basis for systematic evolutionary thinking. The drawback of this focused viewpoint is that it may not engender the degree of divergent thinking needed to predict or cope with major discontinuities: this would call for a metaphorical framework. At the same time the inevitable uncertainties and need for interpretation mean that the output can only be explanatory. It can provide a reasoned justification for expecting certain events and trends and hence suggesting certain responses, but this represents an aid to judgement rather than a substitute.

\section{Metaphorical mode}

Metaphorical applications are used to inspire fresh thinking about a situation and possible responses. One of their key benefits is that they can be used in unusual conditions where an analytical understanding may not be possible. Such conditions might include radically new ventures and highly unstable environments. A powerful and enduring strategy metaphor is the presentation of the strategies of Alexander the Great (Bose 2003, Kurke 2004). 


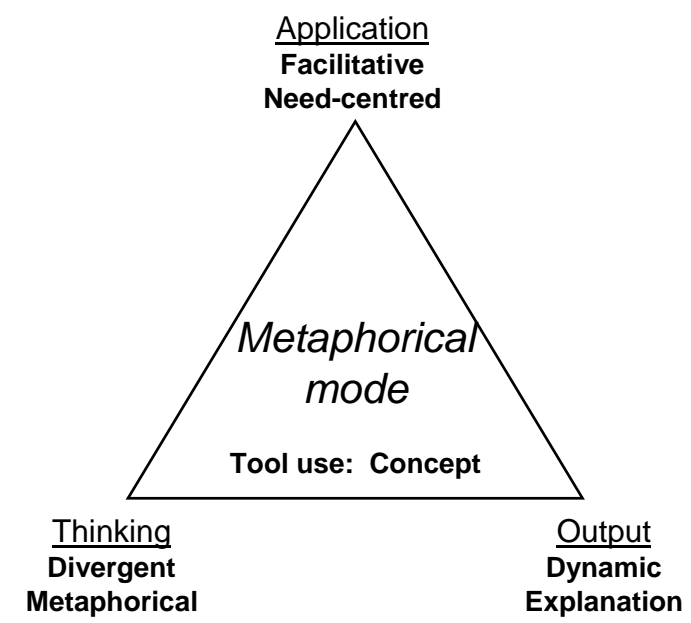

Figure 4: Metaphorical mode of application

The power of metaphors lies in their expression of experiential knowledge not amenable to literal description and in their ability to lead to insights into mechanisms linking observed events (Tsoukas 1991). Since their value lies in expression and thought processes, effective metaphorical applications are facilitative rather than analytical. Their qualities lend them to inspire unconventional, divergent thinking. They have the potential to generate dynamic output even where analytical dynamic thinking is inhibited by uncertainty, complexity or lack of data. However, their value relies largely on their interpretation by the user: metaphorical applications must be need-centred in terms of both the cognitive preferences of the users and the translation between literal and metaphorical explanation. For this reason, metaphorical tools are arguably best presented without over-interpretation, to avoid inhibiting the user's own responses (Gray 2003).

Metaphorical applications may be developed further to promote analogical reasoning in which parallels are explored in a more structured fashion (Tsoukas 1991). In such applications, the danger of drawing on false parallels can be reduced by using a disciplined approach and by looking for where the metaphor breaks down (von Ghyczy 2003, Gavetti and Rivkin 2005). Where this is done, the exercise takes on the characteristics of the facilitative mode of application.

\section{Facilitative mode}

Facilitative applications aid the strategy activity by fostering creativity and structuring communication. Suited to strategy workshops, techniques often used in this mode include SWOT and TOWS techniques (Weihrich 1982), the Delphi process (Dalkey and Helmer 1963) and scenario planning. 


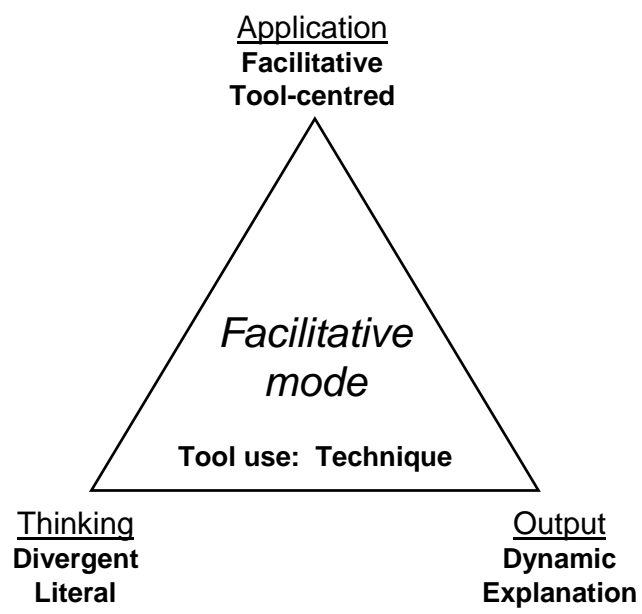

Figure 5: Facilitative mode of application

Because a technique can only provide facilitation to the extent that its content and structure are reflected in the activity, effective facilitative applications will be tool-centred. The categories they provide can be used to inspire expansive, divergent thinking about possible future strategies, but can also bound thinking. For example, the four categories in SWOT and TOWS frame and limit the thinking and discussion (Clegg, Carter and Kornberger 2004). Similarly, where scenario planning is structured around a $2 x 2$ matrix this tends to close thinking in spite of the divergent potential of the basic scenario planning concept. Facilitative applications should be future oriented, and to this extent produce dynamic output, although this must usually be driven by the users as the tool will often not provide a specific heuristic for thinking dynamically. As such, dynamic output may be hard to achieve; the outcome will be driven by the perspective held by participants at a point in time. The value gained from a facilitative application is often as much in the understanding gained by participants as in any specific outcome. Thus the output is a form of explanation in the sense of clarifying ideas, issues and strategies; subsequent analysis would normally be needed before prescribing action.

\section{Interventionist mode}

Interventionist tool applications involve using ideas as a blueprint for action rather than simply as an input to decision making. They are useful when a tool suggests better performing processes or a defined approach with which participants can identify. A key feature distinguishing this mode of application is that it typically involves substantial commitment of people and funds, and has organisation-wide implications. Tools that lend themselves to interventionist application include the balanced scorecard (Kaplan and Norton 1992), total quality management and benchmarking (Camp 1989). 


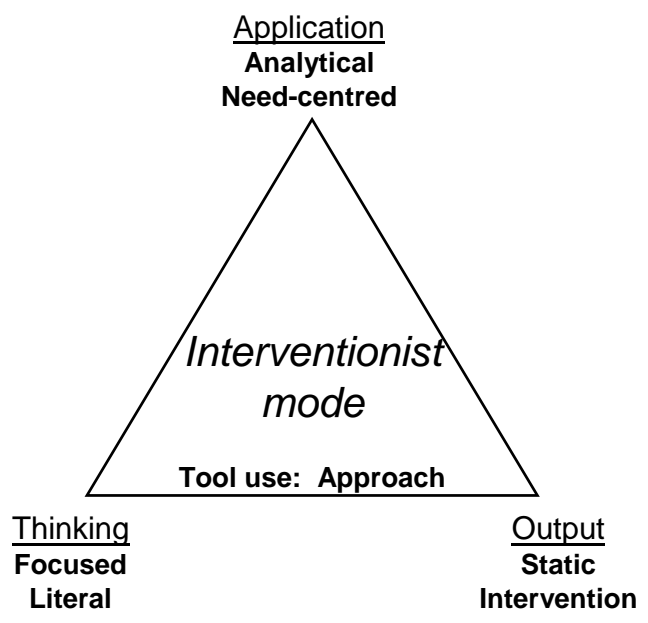

Figure 6: Interventionist mode of application

Because of the institutional implications of an interventionist tool application, it must be well matched to the situation (need-centred). This makes effective tool adaptation especially critical to the success of this mode of application. The high level of commitment involved typically has to be justified in terms of tangible expected benefits, so an analytical relationship will need to be shown between components of the exercise and desired outcomes. This process inherently focuses thinking and action on the specified tool and application. Once implementation is complete, institutionalised aspects of the tool application will be difficult to change and hence relatively static.

\section{Application of the typology}

The value of the typology in terms of potential application lies in the synthesis and codification of key issues in tool usage. It could be used to encourage and help to achieve tool adaptation whose characteristics are readily understood (one of five modes) and which is coherent in terms of the inter-relationship between functions, characteristics and application. By providing a means for prior reflection on tool choice and application, it could help reduce the framing effect that can lead to detrimental effects in tool use. Given its derivation from post-experience strategy teaching, the typology is likely to be well suited to use in teaching, mentoring or facilitation. For experienced users it may codify existing knowledge and legitimise existing flexibility in tool application.

The potential for application of the typology is illustrated by the following three hypothetical applications of the balanced scorecard. The balanced scorecard was proposed by Kaplan and Norton (1992) as an approach to tracking a firm's performance that takes into account process, innovation and customer objectives as well as the financial position. In working with the scorecard they also found it performed an integrative function by bringing together disparate measures in a single report, and hence helped the senior management team to clarify and operationalise strategy.

\section{Application 1}

In this application, a large firm with a degree of decentralised decision making seeks to improve the focus of its managers on a consistent strategic objective. It chooses to apply the 
balanced scorecard substantially as advocated by Kaplan and Norton (1996), linking its strategy with a set of well chosen performance indicators and using this process to communicate the strategy internally and achieve greater goal congruence. This application of the balanced scorecard uses the interventionist mode; its success lies in how effectively it can be integrated with the operation of the firm. The application must be need-centred: the choice of objectives, measures and cause-effect linkages is both crucial and challenging (Ahn 2001). The application should also be analytical, undertaking in full each of the steps such as identifying cause-effect chains; loose application could produce an unbalanced set of indicators that are poorly linked to the firm's strategy. When implemented, the application will promote thinking that is focused on the chosen sets of indicators at the expense of others. This could inhibit the firm's response to environmental change and hence become counter-productive (Ahn 2001), reflecting the static nature of this application. This might be addressed by reviewing the sets of indicators on a regular basis.

\section{Application 2}

This application is for a small but growing high technology firm. The business owners and managers do not favour a mechanised approach, emphasising instead the maintenance of good customer relationships and an intuitive understanding of the business. The rapid evolution of their business model and environment indicate against complex sets of targets and the small, centralised nature of the firm mean that the integrative function of the balanced scorecard is not needed.

What is needed is a tool that legitimises and structures strategic rather than operational thinking. The balanced scorecard could meet this need in that it links strategy with specific business activities such as maintaining customer relationships. Applied in facilitative mode, it could promote strategic understanding in the firm even if not formally implemented as a measurement system. The exercise would be more constructive if oriented to future aspirations, beyond immediate activities and performance; this would mean using the scorecard concepts to promote divergent thinking that is not anchored in current processes. The discussion would be more valuable if it was tool-centred in the sense of making full use of techniques in the balanced scorecard such as the four perspectives and cause-effect chains. If this was done the exercise would provide a check, not just an affirmation, of existing processes and activities.

\section{Application 3}

Application 3 is for a public health authority responsible for a range of healthcare services in its region. It faces externally imposed performance targets and mandatory dissemination of specified performance data. The management team decide not to attempt a full implementation of the balanced scorecard, suspecting another measurement initiative would not be welcomed. However, they want to develop a clearer picture of how the mandated targets and measures relate to the strategic objectives they are developing for the authority. Given its integrative elements, they find the balanced scorecard suitable for this purpose, adapting it for an application that corresponds with the analytical mode. They use a toolcentred application, commissioning full analytical use of techniques including cause-effect chains and stipulations to balance indicators between leading and lagging, financial and nonfinancial and so on. The discipline this imposes on an otherwise political process is a key benefit of the application. Other characteristics of the analytical mode also fit well with the needs and context: focus rather than expansive thinking, and explanation rather than intervention. The static nature of the exercise - rooted in current measures and strategy - 
would have to be addressed by other more future oriented exercises that would use a different mode of tool application.

\section{Discussion}

The key conceptual contributions of the typology are to highlight the centrality of user adaptation of tools and to begin to codify the effects of tool enactment. It is hoped that it will stimulate further work in this area, which has arguably been under-represented in the literature relative to its practical importance. An area that could be explored further is the effect of the context on tool enactment. Outside of post-experience teaching, users are likely to have less time and propensity for reflectiveness, and will vary in levels of experience and education. Other factors that will interact with tool application include the team, the organisation and the community of practice (Wilson and Jarzabkowski 2004). These different contexts could produce variants or refinements to the typology; they have already given rise to alternative approaches matching strategy activity to conditions (Daft and Weick 1984, Jarzabkovski 2004).

It has been suggested that useful theory cannot be simultaneously general, accurate and simple (Daft and Weick 1984). The major theoretical hypothesis in the typology is the set of five generic application modes. This emphasises the simple (five types) and the general (suggests applicability across contexts, environments and tools), but at the expense of precision and detail. Like many strategy tools, the typology does not provide a blueprint for its use but leaves scope for the user's own interpretation to match their specific needs and context. At the expense of generality, more specific guidance might be developed for particular contexts and tools.

The three applications outlined in the previous section illustrate the potential use of the typology in tool teaching and application. It might also be used by tool originators to improve the pragmatic validity of new tools (Worren, Moore and Elliott 2002) by considering their possible modes of application and hence giving better application guidance. In either case, the limitations given above should be taken into account: the generic application modes provide a coherent set of choices to be made in applying strategy tools, but cannot be advocated as a ready-made solution to designing specific applications.

The most prominent empirical work on the application of strategy tools is that reported by Rigby (1993, 2001). This extensive questionnaire-based work could be complemented by intensive studies of specific tool application cases. These could be used to develop and validate the typology presented here. Users could be questioned about their selection and implementation choices, reasoning and outcome. The responses could then be related to the typology during analysis, checking whether the dimensions and application modes adequately characterise the reported application activity. The cases might also be used to check whether applications close to the generic application modes are more successful than those that are not, hence beginning to validate this central hypothesis of the typology. A later step would be to study cases in which the typology is actively used in designing tool applications. This work could validate such use of the typology and hence reduce the current recommended limits to its practical application.

In conclusion, the paper provides a framework that it is hoped will encourage and legitimise reflective user interpretation of strategy tools and stimulate further work that will improve our understanding of this key strategy activity. 


\section{References}

Abrahamson, E., Fairchild, G. (1999), "Management fashion: lifecycles, triggers, and collective learning processes”, Administrative Science Quarterly Vol 44 No 4, pp.708-740

Ahn, H. (2001), “Applying the balanced scorecard concept: an experience report”, Long Range Planning Vol 34, pp.441-461

Armstrong, J.S., Brodie, R.J. (1994), "Effects of portfolio planning methods on decision making: experimental results”, International Journal of Research in Marketing Vol 11, pp.73-84

Barney, J. (2002), Gaining and Sustaining Competitive Advantage, Second Edition, Prentice Hall, New Jersey

Black, J.A., Boal, K.B. (1994), "Strategic resources: traits, configurations and paths to sustainable competitive advantage”, Strategic Management Journal Vol 15, pp.131-148

Bose, P. (2003), Alexander the Great's art of strategy: the timeless leadership lessons of history's greatest empire builder, Gothan/Penguin

Camp, R.C. (1989), Benchmarking: the search for industry best practices that lead to superior performance, Quality Resources

Campbell-Hunt, C. (2000), "What have we learned about generic competitive strategy? A meta-analysis”, Strategic Management Journal Vol 21 No 2, pp.127-154

Clegg, S., Carter, C., Kornberger, M. (2004), “Get up, I feel like being a strategy machine”, European Management Review Vol 1, pp.21-28

Crainer, S. (1996), “The rise of guru scepticism”, Management Today, March, pp.48-52

Daft, R.L., and Weick, K.E. (1984), “Toward a model of organizations as interpretation systems”, Academy of Management Review Vol 9 No 2, pp.284-295

Dalkey, N., Helmer, O. (1963), “An experimental application of the Delphi method to the uses of experts”, Management Science Vol 9 No 3, pp.458-467

deKare Silver, R. (1997), Strategy in Crisis: Why business urgently needs a completely new approach, Macmillan

Doty, D.H and Glick, W.H. (1994), "Typologies as a unique form of theory building: toward improved understanding of modelling”, Academy of Management Review Vol 19 No 2, pp.230-251

Gavetti, G., Rivkin, J. (2005), "How strategists really think: tapping the power of analogy", Harvard Business Review, Vol 83 No 4, pp.54-63

Graetz, F. (2002), "Strategic thinking versus strategic planning: towards understanding the complementarities”, Management Decision Vol 40 No 5/6, pp.456-462 
Gray, D. (2003), “A gallery of metaphors”, Harvard Business Review Vol 81 No 9, pp.92-3

Hamel, G. and Prahalad, C.K. (1989), “Strategic intent”, Harvard Business Review Vol 67 No 3, pp.63-76

Harrison, E.F. (1999), The Managerial Decision-Making Process, Houghton Mifflin

Hill, C.W.L., Jones, G.R., and Galvin, P. (2004), Strategic Management: an Integrated Approach, John Wiley Australia

Hodgkinson, G.P., Bown, N.J., Maule, A.J,, Glaister, K.W., and Pearman, A.D. (1999), "Breaking the frame: an analysis of strategic cognition and decision making under uncertainty”, Strategic Management Journal Vol 20 pp.977-985

Hodgkinson, G.P., Johnson, G., Whittington, R., and Schwarz, M. (2005), The role and importance of strategy workshops: findings of a UK survey, Advanced Institute of Management Research, London

Jarzabkowski, P. (2004), “Actionable strategy knowledge: a practice perspective”, in Academy of Management Best Conference Paper Proceedings. Academy of Management, New Orleans

Johnson, G., Melin, L., and Whittington, R. (2003), "Micro strategy and strategizing: towards an activity based view”, Journal of Management Studies Vol 40 No 1, p.3

Johnson, G., Scholes, K., Whittington, R. (2004), Exploring corporate strategy: text and cases, FT Prenctice Hall

Kaplan, R.S. and Norton, D.P. (1992), "The balanced scorecard - measures that drive performance”, Harvard Business Review, Vol 70 No 1, pp.71-79

Kaplan, R.S., Norton, D.P. (1996), "Linking the balanced scorecard to strategy”, California Management Review Vol 39 No 1, pp.53-79

Kurke, L.B. (2004), The Wisdom of Alexander The Great: Enduring Leadership Lessons From The Man Who Created An Empire, AMACOM, New York

Lambert, D., Slater S. (1999), "First, fast and on time: the path to success, or is it?", Journal of Product Innovation Management Vol 16, pp.427-438

LeBoeuf, R.A. and Shafir, E. (2003), "Deep thoughts and shallow frames: on the susceptibility to framing effects”, Journal of Behavioural Decision Making, Vol 16 No 2, pp.77-92

Mathews, J.A. (2005), “Strategy and the crystal cycle”, California Management Review Vol 47 No 2, pp.6-32

Miles, R. E., Snow, C.C. (1978), Organizational strategy, structure, and process. McGrawHill, New York 
Mintzberg, H., Ahlstrand, B. and Lampel, J. (1998), Strategy safari: the complete guide through the wilds of strategic management. Pearson Education, Harlow

Nelson, D.L., Quick, J.C. (1996), Organizational Behavior: The Essentials, West Publishing, St. Paul MN, USA

Porter, M.E. (1980), Competitive Strategy: Techniques for Analyzing Industries and Competitors, The Free Press (Macmillan), New York

Porter, M.E. (1985), Competitive Advantage: creating and sustaining superior performance, The Free Press (Macmillan), New York

Prahalad, C. K. and Hamel, G. (1990), “The core competence of the corporation”, Harvard Business Review, Vol 68 No 3, pp.79-91

Rigby, D. (1993), “How to manage the management tools, Planning Review Vol 21 No 6, pp.8-15

Rigby, D. (2001), "Management tools and techniques: a survey", California Management Review Vol 43 No 2, pp.139-160

Seely Brown, J., Duguid, P. (2000), "Balancing act: how to capture knowledge without killing it”, Harvard Business Review Vol 78 No 3, pp.73-80

Teece, D.J., Pisano,G., Shuen, A. (1997), "Dynamic capabilities and strategic management”, Strategic Management Journal Vol 18 No 7, pp.509-533

Tsoukas, H. (1991), “The missing link: a transformational view of metaphors in organization science”, Academy of Management Review Vol 16 No 3, pp.566-585

Tsoukas, H. (1993), "Analogical reasoning and knowledge generation in organization theory”, Organization Studies Vol 14 No 3, pp.323-346

Von Ghyczy, T. (2003), “The fruitful flaws of strategy metaphors”, Harvard Business Review Vol 81 No 9, pp.86-94

Weihrich, H. (1982), “The TOWS matrix - a tool for situational analysis”, Long Range Planning Vol 15 No 2, pp.54-66

Wernerfelt, B. (1984), “A resource-based view of the firm”, Strategic Management Journal Vol 5 No 2, pp.171-180

Whittington, R. (1996), “Strategy as practice”, Long Range Planning Vol 29 No 5 pp.731735

Wilson, D., Jarzabkowski, P. (2004), “Thinking and acting strategically: new challenges for interrogating strategy”, European Management Journal Vol. 1, pp.14-20

Worren, N., Moore, K., and Elliott, R. (2002), "When theories become tools: toward a framework for pragmatic validity”, Human Relations Vol 55 No 10, pp.1227-1250 